\section{Routes to living on the land}

James D. Robertson

The Colonisation of Land: Origins and Adaptations of Terrestrial Animals.

By Colin Little.

Cambridge University Press: 1983.

Pp.290. £55, \$99.50.

To A biologist, the colonization of land by animals first conjures up a simple progressive sequence - lungfish-like creatures evolving into amphibians, some of which became better adapted to drier conditions as reptiles, and from the latter group a line arising which led to the mammals. But such a picture ignores the many terrestrial invertebrates. The chordate groups constitute only one of about thirty phyla, and nine of the remaining twenty-nine invertebrate phyla contain members living on land, the most abundant being arthropods, gastropod molluscs and earthworms.

Dr Little has undertaken the task of evaluating the literature on the probable evolution of the terrestrial members of each phylum from an aquatic medium, and the much greater volume of work available on the morphological and physiotogical adaptations to the new environment, especially in relation to salt and water balance (including permeability, nitrogenous excretion, respiration and reproduction). Colonization of land from the sea has four possible routes - directly via the marine littoral zone; via mangroves and the salt-marsh habitat; from brackish and fresh water; or through the subterranean interstitial ground water between sea, fresh water and land. Then, of course, there is the reverse movement of terrestrially adapted animals back to an aquatic environment.

Animals on land vary in the degree to which they are completely emancipated from water. Thus different families of land-crabs seem to have reached land via the marine littoral or brackish water route; crabs have to go back to the sea to breed, but their gill filaments do not collapse when the crabs are out of water and there is usually increased vascularization of the gill chambers with a thinning of the cuticle in the upper parts to form lungs. By contrast, other land crustaceans such as isopods and amphipods are considered to have taken the marine littoral route without undergoing substantial structural and physiological changes. The same path seems also to have been used by nemertines and chelicerates, the latter including the arachnids, scorpions and other groups each of which may have arisen at different times from marine ancestors.

Little argues that the interstitial environment in both marine and freshwater sands, and in marine and terrestrial ground water, has been the route to terrestrial soils of

small animals such as protozoans, nematodes and ostracods. There is, he says, even the possibility that the ancestors of myriapods and insects came from a marine interstitial habitat.

From fresh water seem to have come platyhelminths, earthworms and leeches, crayfishes and the vertebrates. Terrestrial molluscs appear to have used three routes - two prosobranch groups arriving via fresh water; another prosobranch group (a family related to the marine intertidal Littorina spp.) via the marine littoral and possibly the mangrove habitat; and the pulmonates from salt marshes.

All the conclusions reached by Little are based on the evidence of present distribution and, especially, on considerations of comparative morphological, behavioural and physiological data, including modifications in excretory organs, integuments, respiratory surfaces, the osmotic and ionic composition of haemolymph and the characteristics of its

\section{Planning prehistory}

\section{Robert Foley}

\section{Ascent to Civilization: The Archaeology of Early Man. \\ By John Gowlett. \\ Collins/Knopf: 1984. Pp.208. \\ f10.95; pbk \$14.95.}

THE character of our own species can be illuminated from a variety of sources. Comparative anatomy, the behaviour of primates, fossil evidence, the pattern of contemporary humans and of their cultures can and have all been used to tell the story of the emergence of man. Books on the subject, stretching back to Lyell, Lubbock and Darwin, have ranged from the dogmatic to the doggedly detailed to the downright lunatic. The latest, by John Gowlett, is based firmly on the archaeological record, concentrates on the material evidence rather than speculation, analogy or theory, and certainly has the advantage over its nineteenth-century forerunners of excellent photographs and diagrams of the sites of early man.

From its title, Ascent to Civilization ought to be extracted highlights from two television series - Jacob Bronowski's The Ascent of Man and Kenneth Clark's Civilization. However, where Bronowski and Clark dwelt on the last two thousand years, Gowlett is interested in the preceding two million, the achievements of which are written in stone and bone. Despite this chronological discrepancy, the book is comparable to those two series in terms of clarity, lavishness and the tracing of cultural development through material products.

Gowlett's task is to document the character of man from the fossil and archaeological evidence of the Stone Age, respiratory pigments, type of nitrogenous excretion, and other features. Indeed, for many the greatest value of the book will be the up-to-date information on the ecological physiology of aquatic and terrestrial groups. The data are given in 49 tables and 132 figures, all of which (apart from the 26 photographs) are redrawn from published work in an eminently clear style. There are 1,525 references and adequate general, taxonomic and author indexes.

As the culmination of ten years' work, Dr Little has produced a valuable book which is written with great clarity. He has brought together an immense amount of information on adaptations to aquatic and terrestrial habitats, particularly in the invertebrate groups, and has put forward reasonable conclusions on the origins of different terrestrial animals from an aquatic habitat.

James D. Robertson is at the Department of Zoology, University of Glasgow.

but the context is provided by discussions of the relationship between hominids and apes, by theories of human evolution, and especially by sections showing the nature of archaeological and palaeoenvironmental methodology. In this, two points stand out. First Gowlett is keen to present the basic evidence of archaeology, not to pursue the labyrinthine history of discovery and terminology. And, second, he is remarkably up-to-date and accurate across an enormous range of time and material. Consequently the book provides an extremely accessible and perceptive account of the Stone Age.

Although Gowlett's principal aim is to show the pattern of prehistory, his own conception of what it means to be human comes through. Man is a planner. His success and uniqueness as a species reflects his ability for forethought, and prehistory records increasing planning and organization of human societies. This emphasis on mental abilities marks a return to earlier views on human evolution, in contrast to the currently popular bioenergetic and mechanistic approaches. Gowlett makes a good case for seeing the human brain as more than an environmental epiphenomenon, and for tracking mental abilities through the archaeological record. But the doubt remains that this is explanation by hindsight. The benefits of planning and forethought seem self-evident now, but the reasons why (despite the costs involved) they should have been selected for in a primate in Africa some two million years ago remain to be revealed. However, in this excellent book Gowlett has made available to a wide audience the wealth of material and methods on which the debate about early man must be based.

Robert Foley is a Lecturer in the Department of Anthropology at the University of Durham. 